\title{
Dose Rate Dependence of Residual Defects in Device Grade Si/SiGe Heterostructures formed by Ion Beam Synthesis.
}

\author{
A.Nejim, F.Cristiano, A.P.Knights, N.P.Barradas, P.L.F.Hemment \\ School of Electronic Engineering, Information Technology and Mathematics, University of Surrey, \\ Guildford, Surrey GU2 5XH, UK \\ P. G. Coleman \\ School of Physics, University of East Anglia, Norwich NR4 7TJ, UK
}

\begin{abstract}
The influence of germanium ion current density on the residual defects in ion implanted $\mathrm{Si} / \mathrm{SiGe}$ heterostructures is investigated. Data from (100) silicon wafers implanted with $400 \mathrm{keV} 9 \times 10^{16} \mathrm{Ge}^{+} / \mathrm{cm}^{2}$ shows that both the nature and concentration profile of residual defects below the amorphised silicon surface layer are highly sensitive to the $\mathrm{Ge}^{+}$current density. Dose rates in the range of $7.3 \times 10^{12} \mathrm{Ge}^{+} / \mathrm{s} . \mathrm{cm}^{2}$ and $1.5 \times 10^{12} \mathrm{Ge}^{+} / \mathrm{s} . \mathrm{cm}^{2}$ corresponding to power loading of $0.47 \mathrm{~W} / \mathrm{cm}^{2}$ and $0.09 \mathrm{~W} / \mathrm{cm}^{2}$ respectively, were investigated in this study. The nature and concentration of the defects was investigated by Rutherford Backscatring Channelling analysis (RBS-c), cross section Transmission Electron Microscopy (xTEM) and Positron Annihilation Spectroscopy (PAS) in conjunction with anodic oxidation and wet etching. RBS-c indicates that by increasing the dose rate from $5 \mu \mathrm{A} / \mathrm{cm}^{2}$ to $13 \mu \mathrm{A} / \mathrm{cm}^{2}$ reduces the thickness of the amorphous layer from $550 \mathrm{~nm}$ to $350 \mathrm{~nm}$. A further increase to $20 \mu \mathrm{A} / \mathrm{cm}^{2}$ inhibits the formation of an amorphous layer due to dynamic annealing. This is associated with a significant increase in the depth profile of interstitial defects down to a depth of $800 \mathrm{~nm}$. As in the case of interstitial defects, there is a considerable enhancement in the depth and concentration of open volume defects with increasing dose rate found by PAS analysis. For the highest dose rate open volume defects extend beyond $1.5 \mu \mathrm{m}$ at a concentration in excess of $1 \times 10^{16} / \mathrm{cm}^{2}$. Post amorphisation with $\mathrm{Si}^{+}$implantation removes all the $\mathrm{Ge}^{+}$implant related defects leaving strain related defects and deep band of end of range defects.
\end{abstract}

\section{INTRODUCTION}

The band gap narrowing due to the valance band offset in epitaxial $\mathrm{Si} / \mathrm{Si}_{1-x} \mathrm{Ge}_{x} / \mathrm{Si}$ heterostructures, introduces opportunities for enhanced electron transport properties. The fabrication of transistors with impressive performance has been reported by a number of groups.[1], [2]. Recent reports of SiGe based devices with $\mathrm{f}(\max )$ of $160 \mathrm{GHz}$, low noise performance, low power consumption, make them suitable for hand held electronic applications [3], [4]. High dose germanium implantation into silicon has been used to fabricate devices [5], [6], [7] and synthesise alloys for photoluminescence[8], [9].

In this work, attempts are made to link the microstructure found in ion beam synthesised $\mathrm{Si}_{1-x} \mathrm{Ge}_{x} / \mathrm{Si}$ heterostructures to the $\mathrm{Ge}^{+}$ion current densities and the power loading on the silicon wafers. The modification of deep defect tails will impact on dopant profiles in these heterostructures. Many of the residual defects following the annealing step span the entire implanted region and will impact on any potential application.

\section{MATERIAL PREPARATION}

The central $5 \mathrm{~cm}$ diameter areas of 3" (100) silicon wafers were implanted with $400 \mathrm{keV} 9 \times 10^{16} \mathrm{Ge}^{+} / \mathrm{cm}^{2}$. These wafers were clamped on aluminium plates at three points on the periphery outside the implanted area. Apart from the heat sinking to the metal plate, there was no background cooling used. Three dose rates of $5 \mu \mathrm{A} / \mathrm{cm}^{2}$, $13 \mu \mathrm{A} / \mathrm{cm}^{2}$ and $20 \mu \mathrm{A} / \mathrm{cm}^{2}$ were used in this study. The beam spot of about $1 \mathrm{~cm}$ diameter was electrostatically scanned using triangular frequency of $59 \mathrm{~Hz}$ in the horizontal direction and $370 \mathrm{~Hz}$ in the vertical direction. The wafers were tilted by $7^{\circ}$. Table I gives details of the intantanous and time average ion beam current densities used for this study.

Samples from the as implanted wafers were taken for Rutherford backscattering and channelling (RBS-c) analysis. Other samples were thinned using anodic oxidation in a 0.05 molar solution of $\mathrm{KNO}_{3}$ in $90 \%$ ethylene glycol and $10 \%$ de-ionised water. This solution produced an anodisation coefficient of $0.25 \mathrm{~nm} / \mathrm{V}$. Using platinum wire as the cathode and the samples as the anode a constant current supply of $50 \mathrm{~mA}$ at $100 \mathrm{~V}$ was used to oxidise $25 \mathrm{~nm}$ per run. This oxide was subsequently removed in HF solution. The process was repeated to remove $750 \mathrm{~nm}$ which represents the top highly damaged layer. These samples were then analysed by Positron Annhilation Spectroscopy (PAS) for deep open volume defect tails.

Material taken from these wafers was subsequently post amorphised to a depth of $1 \mu \mathrm{m}$ using $500 \mathrm{keV}$ $6 \times 10^{15} \mathrm{Si}^{+} / \mathrm{cm}^{2}$ into samples cooled to $150 \mathrm{~K}$ by liquid nitrogen. This material, together with some as implanted samples, was then annealed at $700^{\circ} \mathrm{C}$ for 20 minutes in an RTA unit under nitrogen flowing at 0.65 litre/minute and subsequently analysed with Transmission Electron Microscopy (TEM). 
TABLE I

TABLE OF SAMPLE DETAILS.

\begin{tabular}{||c|c|c|c|c||}
\hline \hline Wafer & $\begin{array}{c}\text { Time } \\
\text { average } \\
\text { density } \\
\mu \mathrm{A} / \mathrm{cm}^{2}\end{array}$ & $\begin{array}{c}\text { Instantaneous } \\
\text { current } \\
\text { density } \\
\mu \mathrm{A} / \mathrm{cm}^{2}\end{array}$ & $\begin{array}{c}\text { Power } \\
\text { loading }\end{array}$ & $\begin{array}{c}\alpha \\
\text { layer } \\
\text { thickness } \\
\mathrm{nm}\end{array}$ \\
\hline \hline $\mathrm{W} 1$ & 1.17 & 20 & 8 & - \\
\hline $\mathrm{W} 2$ & 0.59 & $10-13$ & $5.2-4$ & 350 \\
\hline $\mathrm{W} 3$ & 0.24 & $3-5$ & $2-1.2$ & 550 \\
\hline \hline
\end{tabular}

\section{ANALYSIS}

\section{A. Rutherford Backscattering \& Channeling Measurements}

Accurate Rutherford Backscattering Spectroscopy Channeling (RBS-c) measurements were made to analyse the ion implantation defect profiles in these samples. The DICADA code[10] was used to analyse the channelled spectra by comparing them with those obtained from a perfect crystal, and calculating the number of defects of a specified type as a function of depth that can cause the dechannelling observed.

The near surface regions in W3 and W2 were amorphised. This is reflected in the defect concentration vs depth profiles of these samples shown in figure 1 .

\section{B. Positron Annihilation Analysis}

Controlled-energy PAS was performed using the computer-controlled positron beam at the University of East Anglia (UEA) [11]. A monoenergetic beam of positrons, of energies in the range 0 to $30 \mathrm{keV}$, impinges upon the sample surface in vacuum conditions of $10^{-6} \mathrm{~Pa}$. The mean implantation depth $\bar{z}$ is related to the incident positron energy $(\mathrm{E})$ in $\mathrm{keV}$ by

$$
\bar{z}=(400 / \rho) E^{1.6}
$$

where $\rho$ is the density of the sample. The implanted positrons rapidly thermalise and, while diffusing through the material, may be trapped by vacancy-type defects or reach the surface. At each energy, the annihilation gamma photopeak is accumulated by a Ge detector-amplifiermultichannel analyser system. The extent of the Doppler broadening of the peak is characterised by the sharpness, or S parameter, which is taken as the ratio of counts in the central region to that of the whole peak.

Because the positron implantation profile becomes increasingly extended as the incident positron energy (and hence mean implantation depth) increases, the depth sensitivity of the technique decreases with depth. Furthermore, the fact that the majority of positrons annihilate in vacancies in the large peak just below the surface means that the ability of PAS to study lower-intensity extended vacancytype defect tails is limited. Therefore, combining standard

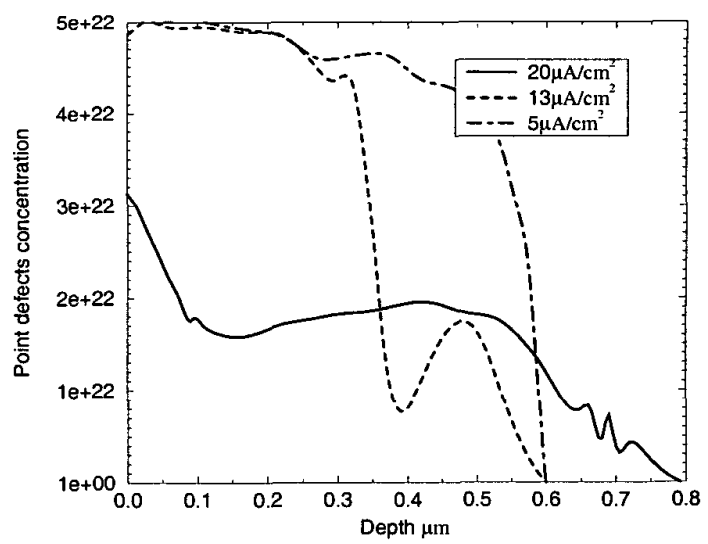

Fig. 1. DICADA analysis of RBS $<100\rangle$ channeled spectra from the three samples W3, W2 \& W1 implanted with $400 \mathrm{keV}$ $9 \times 16 \mathrm{Ge}^{+} / \mathrm{cm}^{2}$ at dose rates of $5 \mu \mathrm{A} / \mathrm{cm}^{2}$ to $20 \mu \mathrm{A} / \mathrm{cm}^{2}$.

non-destructive PAS with anodic oxidation and wet etching of known sample thicknesses, extends this technique by maintainingg near surface resolution at greater depths.

It has been demonstrated experimentally that this thinning process does not introduce damage in the surface region to which positrons are sensitive [12]. The $S$ parameters for the three wafers are shown in figure 2 as a function of depth.

\section{TEM analysis}

Annealed samples with and without post amorphisation were analysed by cross section Transmission Electron Microscopy $(x-T E M)$. Samples were cleaved, glued and cut into $500 \mu \mathrm{m}$ thin sections using a diamond saw, then ground

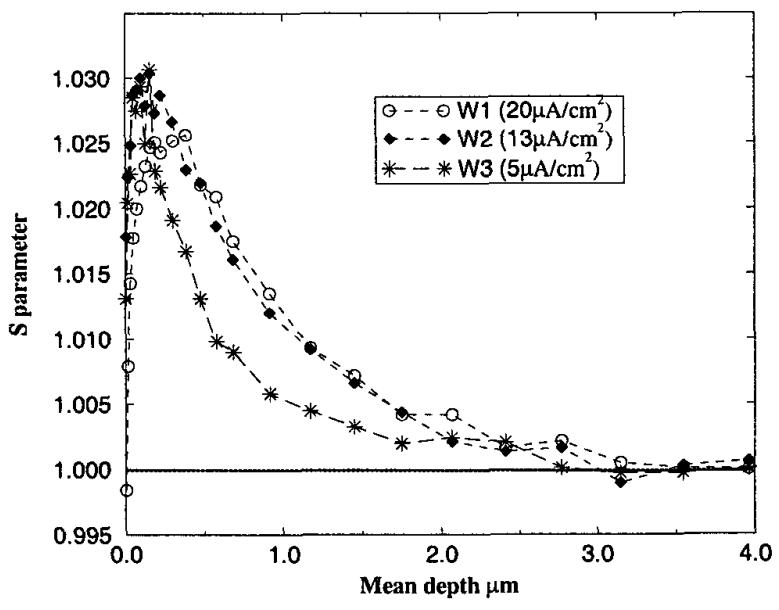

Fig. 2. S parameter from positron annihilation data as a function of mean depth for W3, W2 and W1 following the removal of $750 \mathrm{~nm}$ thick surface kayer. 
down to about $15 \mu \mathrm{m}$ before being loaded into an ion beam miller for a final thinning. The observations were made in a JEOL 2000FX housed at the University of Surrey.

Figure 3 shows micrographs obtained from material implanted with the three dose rates together with a post amorphised and annealed sample from W1. Post amorphised and annealed material from the other two wafers looked similar to that of W1.

\section{RESULTS AND DISCUSSION}

\section{A. Dose Rates $5 \mu \mathrm{A} / \mathrm{cm}^{2}$ to $13 \mu \mathrm{A} / \mathrm{cm}^{2}$}

DICADA analysis of the $<100>$ RBS channeling spectra from W3 and W2 before annealing reveals that by increasing the instantaneous $\mathrm{Ge}^{+}$ion current density from $5 \mu \mathrm{A} / \mathrm{cm}^{2}$ to $13 \mu \mathrm{A} / \mathrm{cm}^{2}$ the amorphous layer thickness is reduced from $550 \mathrm{~nm}$ to $350 \mathrm{~nm}$. For W3, the dechannelling signal below the amorphous layer recovers sharply from $80 \%$ defect concentration down to the unimplanted virgin crystalline quality within $50 \mathrm{~nm}$, as shown in figure 1 . This can be contrasted with a peak of defects trapped $120 \mathrm{~nm}$ below the amorphous crystalline $(\alpha / \mathrm{c})$ interface for W2.

The S parameter extracted from the positron data shown in figure 2 indicate that defects above $10^{16} / \mathrm{cm}^{3}$ extend to a depth of $900 \mathrm{~nm}$ for W3. This is significantly extended to a depth of $1.5 \mu \mathrm{m}$ for $\mathrm{W} 2$.

Following regrowth anneal at $700^{\circ} \mathrm{C}$ there appears to be clear differences between the microstructure of these two samples, as shown in figure $3 \mathrm{a} \& \mathrm{~b}$. Two types of defects can be identified in W3: (1) a band of end of range defects at a depth of $500 \mathrm{~nm}$ and (2) hair pin dislocations threading to the surface. The majority of these are nucleate in the region of the peak of the germanium distribution. In addition to these, a few nucleate at the original amorphous crystalline interface. The microstructure of a sample implanted with a medium dose rate shown in figure $3 \mathrm{~b}$ is dominated by hair pin dislocations nucleating at the $(\alpha / \mathrm{c})$ interface which show an approximate density of $10^{10} / \mathrm{cm}^{2}$. This is about an order of magnitude greater than those found in W3. The hair pins nucleating at the projected range of the germanium could not be observed. This increase in the defects density is thought to be related to either the increase in the roughing of the $(\alpha / c)$ interface with increasing dose rate [13] and/or the increase in the elastic strain energy below the $(\alpha / c)$ interface [14] due to the increase in the point defects as seen from the peak at $500 \mathrm{~nm}$ in figure 1.

\section{B. Dose Rates $13 \mu \mathrm{A} / \mathrm{cm}^{2}$ to $20 \mu \mathrm{A} / \mathrm{cm}^{2}$}

Increasing the dose rate to $20 \mu \mathrm{A} / \mathrm{cm}^{2}$ inhibits the formation of an amorphous layer altogether. This is due to increased power loading which increases the temperature of the wafer during the implant leading to the dynamic annealing of implant induced defects. The DICADA analysis of the RBS-c data shows that the point defect profile extends to $800 \mathrm{~nm}$ deep before the structure recovers back to the unimplanted crystal quality.

Positron annihilation data from the thinned W1 sample indicates similar deep tail of open volume defects extending to $1.5 \mu \mathrm{m}$.

Furthermore the microstructure after the annealing step shown in figure $3 \mathrm{c}$ indicates two distinct regions of high density defects. The near surface layer of $280 \mathrm{~nm}$ which is characterised by a network of dislocations and a lower region of high density damage clusters between $280 \mathrm{~nm}$ $650 \mathrm{~nm}$. A similar microstructure was obtained by Chen [15] following a $160 \mathrm{keV}$ germanium implant into silicon wafers kept at temperatures of $200^{\circ} \mathrm{C}$ and up to $500^{\circ} \mathrm{C}$ which prevented the formation af an amorphous layer.

Finaly, a subsequent deep amporphisation using a cold $500 \mathrm{keV} \mathrm{Si}^{+}$implant prior to the regrowth anneal removes all defects apart from the strain related hair pin dislocations at the peak of the germanium distribution [14] and introduces a simple band of end of range defects at a depth of $1 \mu \mathrm{m}$ as shown in figure $3 \mathrm{~d}$.

\section{Conclusions}

$400 \mathrm{keV}$ germanium ion dose rate is an important factor in determining both the microstructure and the defect tail profiles in the synthesised SiGe alloy. We distingush three different regiemes in this study:

1. Material implanted at $5 \mu \mathrm{A} / \mathrm{cm}^{2}$ shows a sharp $(\alpha / \mathrm{c})$ interface and open volume defect density of above $10^{16} / \mathrm{cm}^{3}$ extending to $900 \mathrm{~nm}$. Following regrowth the microstructure is characterised by a low density $\left(10^{7} / \mathrm{cm}^{2}\right)$ of hair pin dislocations nucleated at the amorphous crystalline interface .

2. Increasing the dose rate to $13 \mu \mathrm{A} / \mathrm{cm}^{2}$ reduces the amorphous thickness by about $200 \mathrm{~nm}$ and introduces a defect peak at $500 \mathrm{~nm}$ below the $(\alpha / \mathrm{c})$ interface. Open volume defects in excess of $10^{16} / \mathrm{cm}^{3}$ extend to $1.5 \mu \mathrm{m}$. The annealed microstructure is dominated by a high concentration $\left(10^{10} / \mathrm{cm}^{2}\right)$ of hair pin dislocations at the $(\alpha / c)$ interface.

3. As the dose rates increases to $20 \mu \mathrm{A} / \mathrm{cm}^{2}$ the power loading of $0.47 \mathrm{~W} / \mathrm{cm}^{2}$ on the wafer prevents the formation of the amorphous layer. The annealed material shows two distinct layers; a band of extended defects from the surface down to $280 \mathrm{~nm}$ above a second band of high concentration dislocations to a depth of $650 \mathrm{~nm}$.

4. Post amorphisation removed all ion implantation related defects from all samples leaving hair pin dislocations at the peak of the germanium profile and a band of end of rage defects at $1 \mu \mathrm{m}$ from the surface.

It remains to be seen if deliberate cooling of the wafers will mitigate some of the effects of the high dose rates seen in this study. 
[1] E.Kasper, H.Kibbel, H.J.Herzog, and A.Gruhle, Jpn. J. Appl. Phys., vol. 33, pp. 2415-2418, 1994.

[2] T.Nakamura and H.Nishizawa, IEEE Trans Elec Devi, vol. 42, pp. 390-398, 1995.

[3] A. Gruhle and A. Schuppen, Thin Solid Films, vol. 294, pp. 246, 1997.

[4] E. deBerranger, S. Bodnar, A. Chantre, J. Kirtsch, A. Monroy, A. Granier, M. Laurens, JL. Regolini, and M. Mouis, Thin Solid Films, vol. 294, pp. 250, 1997.

[5] A.Fukami, K.Shoji, T.Nagano, and C.Y.Yang, Appl. Phys. Lett., vol. 57 , no. 22 , pp. $2345-2347,1990$.

[6] C.R. Selvakumar and B. Hecht, IEEE Electron Device Lett., vol. 12, no. 8, pp. 444-446, 1991.

[7] S.Lombardo, A.Pinto, V.Raineri, P.Ward, G.Larosa, G.Privitera, and S.U.Campisano, Elec. Dev. Lett., vol. 17, no. 10, pp. 485-487, 1996.

[8] P. Songsiriritthigul, G. Holmen, and E. Olsson, Nucl. Inst. Meth., vol. 122, pp. 630-634, 1997

[9] A. PerezRodriguez, A. RomanoRodriguez, C. Serre, L. CalvoBarrio, R. Cabezas, O. GonzalezVarona, JR. Morante, R. Kogler, W. Skorupa, and A. Rodriguez, Nucl. Inst. Meth., vol. 120, pp. 173-176, 1996.

[10] K. Gärtner and A. Uguzzoni, Nucl. Inst. Meth., vol. B 67, pp. $189,1992$.

[11] N.B. Chilton and P.G. Coleman, Measurement Science \& Technology, vol. 6, pp. 53-59, 1995.

[12] A.Nejim, A.P.Knights, C Jeynes, P.G.Coleman, and C.J. Patel, J. Appl. Phys., vol. 83, pp. 3565-3573, 1998.

[13] F. Cristiano, Ph.D. thesis, University of Surrey, 1998.

[14] F. Cristiano, A. Nejim, B.de Mauduit, A. Claverie, and P.L.F.Hemment, Nucl. Inst. Meth, vol. 120, pp. 156-160, 1996.

[15] Nan Xiang Chen, R. Schork, and H. Ryssel, Nucl. Inst. Meth, vol. B96, pp. 286-289, 1995.

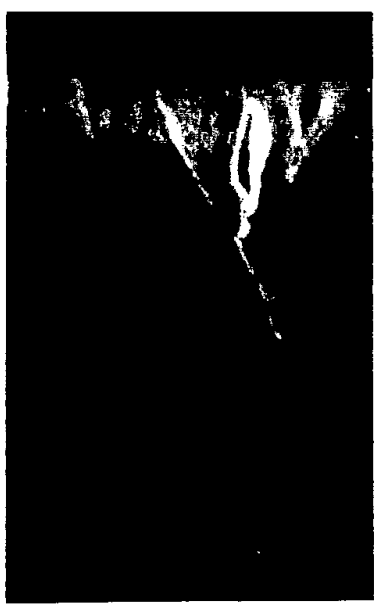

a

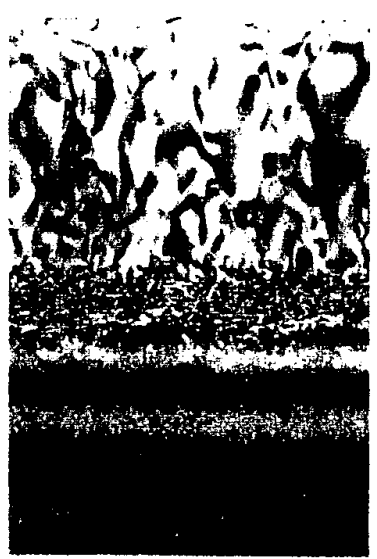

b

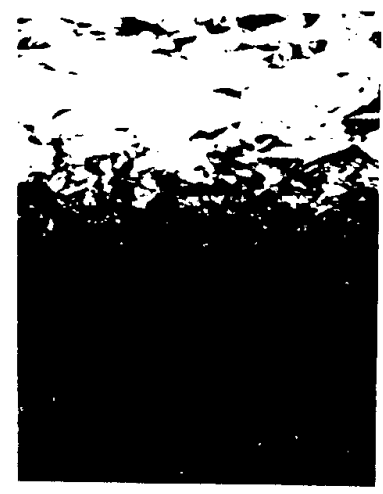

C

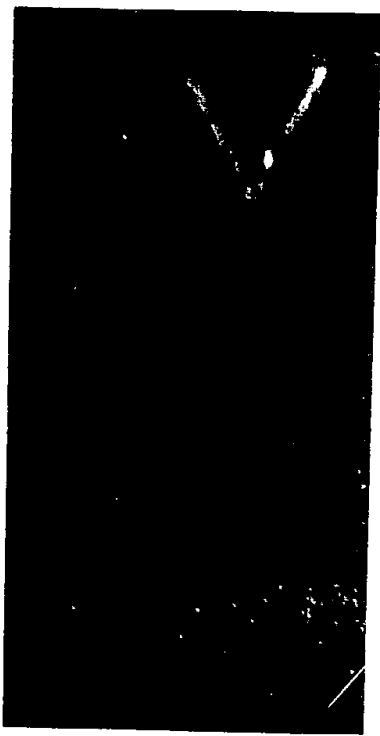

$500 \mathrm{~nm}$

Fig. 3. XTEM micrographs from samples implanted with a) $5 \mu \mathrm{A} / \mathrm{cm}^{2}$, b) $\left.13 \mu \mathrm{A} / \mathrm{cm}^{2}, \mathrm{c}\right) 20 \mu \mathrm{A} / \mathrm{cm}^{2} \mathrm{~W} 3$ and d) $20 \mu \mathrm{A} / \mathrm{cm}^{2} \mathrm{~W} 3 \mathrm{post}$ amorphised 